Rev. Bras. Reprod. Anim., v.44, n.4, p.150-158, out./dez. 2020

\title{
Maturação in vitro de oócitos bovinos é negativamente afetada por CHIR99021, inibidor específico de GSK3
}

In vitro maturation of bovine oocytes is negatively affected by CHIR99021, a specific inhibitor of GSK3

\section{Laura Mathias Barrosoํ, Alinne Glória Curcio', Angelo José Burla Dias ${ }^{12}$}

\begin{abstract}
${ }^{1}$ Laboratório de Reprodução e Melhoramento Genético Animal, Centro de Ciências e Tecnologias Agropecuárias, Universidade Estadual do Norte Fluminense Darcy Ribeiro - Campos dos Goytacazes, RJ/Brasil

${ }^{2}$ Laboratório de Reprodução e Melhoramento Genético Animal, Centro de Ciências e Tecnologias Agropecuárias, Universidade Estadual do Norte Fluminense Darcy Ribeiro (Avenida Alberto Lamego, 2000 - Parque Califórnia, Campos dos Goytacazes/RJ - Brasil)
\end{abstract}

\begin{abstract}
Resumo
A enzima glicogênio sintase quinase-3 (GSK3) atua em várias vias de sinalização pela fosforilação e desfosforilação de proteínas, participando de várias funções celulares. Poucos estudos descrevem sua participação na maturação in vitro (MIV) de oócitos bovinos, mas sabe-se que sua inibição inespecífica tem um impacto negativo nesse processo. O objetivo deste trabalho foi avaliar o efeito de CHIR99021, inibidor específico da GSK3, em diferentes aspectos da MIV de complexos de cumulusoócito (CCOs) bovino e seu impacto na produção in vitro. Os CCOs foram aspirados de ovários de vacas abatidas e maturados em meio suplementado com $0 ; 1,5 ; 3,0$ e $6,0 \mu \mathrm{M}$ de CHIR99021. A análise estatística dos resultados por regressão linear $(\mathrm{p} \leq 0,01)$ mostrou que após $22 \mathrm{~h}$ de MIV, o tratamento causou redução dose-dependente no grau de expansão das células cumulus; na viabilidade de oócitos avaliada por coloração com calceína-AM e iodeto de propídio; nas taxas de maturação nuclear, e migração de grânulos corticais avaliadas por marcação com orceína acética a $2 \%$ e com lectina Lens culinaris-FITC (LCA), respectivamente, além de uma redução na produção de blastocistos. Assim, conclui-se que o CHIR99021 interfere negativamente, de forma dose-dependente na MIV de oócitos bovinos, sugerindo a importância da GSK3 na maturação nuclear e citoplasmática, com consequente impacto para a produção in vitro de embriões bovinos.
\end{abstract}

Palavras-chave: glicogênio sintase quinase-3, maturação nuclear, grânulos corticais, produção in vitro de blastocisto.

\begin{abstract}
The enzyme glycogen synthase kinase-3 (GSK3) acts in several signaling pathway through phosphorylation and protein dephosphorylation, participating in various cellular functions. Few studies describe its participation in the in vitro maturation (IVM) of bovine oocytes, but its nonspecific inhibition is known to have a negative impact on this process. The objective of this work was to evaluate the effect of CHIR99021, specific inhibition of GSK3, on different aspects of the in vitro maturation of bovine cumulus-oocyte (COCs) complexes. COCs were aspirated from ovaries of slaughtered cows and matured in medium supplemented with0; 1.5; 3.0 and $6.0 \mu M$ CHIR99021. Statistical analysis of the results by linear regression $(p \leq 0.01)$ showed that after 22 hours of IVM the treatment caused dose-dependent reduction in the degree of cumulus cell expansion; oocyte viability evaluated by staining with calcein-AM and propidium iodide; rates of nuclear maturation and migration of cortical granules evaluated by labeling with $2 \%$ acetic orcein and Lens culinaris-FITC (LCA), respectively; and a reduction in the of blastocyst rate. It is concluded that CHIR99021 interferes negatively, in a dose-dependent manner in the IVM of bovine oocytes, suggesting the importance of GSK3 in nuclear and cytoplasmic maturation, with a consequent impact on the in vitro bovine embryos production.
\end{abstract}

Key words: glycogen synthase kinase-3; nuclealr maturation; cortical granules; in vitro blastocysts production.

\section{Introdução}

A enzima glicogênio sintase quinase-3 (GSK3) é uma serina-treonina quinase que fosforila vários substratos, participando de importantes vias de sinalização (Cormier e Woodgett, 2017). Inicialmente, seu

${ }^{1}$ Correspondência: angeloburlauenf@gmail.com

Recebido: 12 de fevereiro de 2020

Aceito: 17 de junho de 2020 
mecanismo de ação foi descrito por sua participação no metabolismo energético celular através da via de sinalização da insulina (Embi et al., 1980). Entretanto, essa enzima também participa do controle da síntese protéica, multiplicação e diferenciação celular, dinâmica dos microtúbulos e apoptose (Forde e Dale, 2007).

O mecanismo mais estudado para o controle da atividade da GSK3 é por meio da via PI3K/Akt. Nessa via, fatores de crescimento e citocinas ativam receptores transmembras aumentando a atividade da fosfatidil inositol-3-cinase (PI3K), o que leva a conversão de PI(3,4)P2 em PI(3,4,5)P3, ativando a proteína quinase $\mathrm{B}$ (PKB/AKT). Esta fosforilação é dependente da ação do phosphoinositidio dependente de quinase1 (PDK1) e do mammalian target of rapamycin complex 2 (mTORC2). Uma vez ativa, AKT fosforila GSK3, tornando-a inativa (Cohen e Frame, 2001). Mecanismos que envolvem enzimas do tipo quinase, como a proteína quinase A (PKA), proteína quinase C (PKC), p70S6 quinase, também são capazes de inativar GSK3 (Beurel et al., 2015).

GSK3 possui mais de cem substratos conhecidos. Um de seus principais alvos é a glicogênio sintase (GS), que controla a formação de glicogênio pela célula. A inibição da GSK3 reduz a gliconeogênese, pois mantém a GS ativa, permitindo sua ação na conversão de glicose-6-fosfato em glicogênio (Sutherland, 2011). GSK3 também é um fator chave na via WNT/ $\beta$-catenina. Quando GSK3 está fosforilada (inativa) deixa de degradar $\beta$-catenina nos proteossomos - então, este mensageiro transloca-se para o núcleo e estimula a transcrição dos genes WNTs. Foi demonstrado que esses genes participam do controle da embriogênese e da diferenciação celular (Tribulo et al., 2017a, 2017b). Os fatores de transcrição eiF2B, CREB e c-Jun, e as proteínas associadas a microtúbulos (MAPs) também são substratos importantes da GSK3. A proteína eiF2B cataliza a substituição da guanina no DNA e sua inibição por GSK3 reduz os mecanismos de tradução; CREB atua no estímulo a produção de AMPc e quando fosforilados por GSK3 tem sua atividade transcricional induzida; c-Jun está envolvida na proliferação celular, sobrevivência e morte e a inibição de GSK3 potencializa a sua ação oncogênica permitindo sua ligação ao DNA; proteína Tau participa da dinâmica de estabilização dos microtúbulos mediada pela fosforilação e desfosforilação de GSK3 (Sutherland, 2011).

Neste sentido, lítio e os inibidores de quinases dependentes de ciclina (CDKs), como o 6BIO, são exemplos de inibidores não específicos usados em diferentes tipos celulares (Jope, 2003; Sklirou et al., 2017), incluindo CCOs bovinos (Uzbekova et al., 2009), para aumentar a compreensão do papel de GSK3 em diferentes vias metabólicas e tipos celulares. Entretanto, $\mathrm{LiCl}_{2}$ também pode atuar em outras quinases, como MAPK14, MAPK2 e PKB/AKT (Jope, 2003; Acevedo et al., 2007; Uzbekova et al., 2009; Sklirou et al., 2017). Atualmente, os CHIR inibidores (CHIR98014, CHIR98023, CHIR99021) são reconhecidos como os inibidores mais potentes e específicos dessa enzima (Ring et al., 2003), competindo com as ligações ATP, fosforilando-a e tornando-a inativa. Essas substâncias são capazes de inibir ambas as isoformas de GSK3 (Ser ${ }^{9}$ GSK3 $\alpha$ e Ser $^{21}$ GSK3 $\beta$ ) sem alterar a atividade de outras quinases e com baixa toxicidade (Woodgett, 1990; Bain et al., 2007; Naujok et al., 2014).

A participação dessa enzima na maturação in vitro (MIV) de oócitos foi demonstrada em camundongos (Wang et al., 2003; Acevedo et al., 2007), sapos (Sarkissian et al., 2004), porcos (Pelech et al., 2008) e vacas (Tomek e Smiljakovic, 2005;Uzbekova et al., 2009). Tomek e Smiljakovic (2005) demonstraram que há aumento na fosforilação da GSK3 nos oócitos logo após a quebra da vesícula germinativa entre 6 e 8 h de MIV. Uzbekova et al., (2009) identificaram GSK3 $\alpha$ e GSK3 $\beta$ nos CCOS, em que GSK3 $\beta$ é mais abundante nas células do cumulus do que no oócito. Estes autores relataram que a inibição de GSK3 reduz o grau de expansão das células dos cumulus e a taxa de maturação nucler. Por outro lado, Aparicio et al. (2010) relataram aumento da taxa de blastocisto utilizando $3 \mu \mathrm{M}$ de CHIR99021, porém o uso de $20 \mathrm{mM}$ de $\mathrm{LiCl}_{2}$ reduziu o número de embriões, após oito dias de cultivo. Concentrações elevadas de CHIR99021 $(10 \mu \mathrm{M})$ também reduziram a proporção de blastocistos in vitro (Tribulo et al., 2017a).

Trabalhos prévios utilizando inibidores inespecíficos podem refletir efeitos obtidos a partir da inibição de mais de um alvo enzimático. Apesar da participação da GSK3 ter sido demonstrada na maturação, nenhum novo estudo foi desenvolvido na última década demonstrando como a modulação exclusiva de sua atividade influencia nesse processo e subsequente desenvolvimento embrionário. Assim, o objetivo deste estudo foi avaliar o efeito de CHIR99021, inibidor específico da GSK3, em diferentes aspectos da MIV de CCOs bovinos e seu impacto na produção in vitro.

\section{Material e Métodos}

Todos os reagentes utilizados foram adquiridos da Sigma Aldrich $^{\circledR}$ (San Diego, Califórnia, 
Barroso et al. Maturação in vitro de oócitos bovinos é negativamente afetada por CHIR99021, inibidor específico de GSK3

Estados Unidos), exceto aqueles especificados no texto.

\section{Maturação in vitro (MIV)}

Folículos de 3 a $8 \mathrm{~mm}$ foram aspirados de ovários de vacas abatidas em matadouros locais. Os CCOs de grau 1 e 2 foram selecionados e maturados em gotas de $100 \mu \mathrm{L}$ (20 CCOs/gota) (TCM 199, soro fetal bovino 5\%; penicilina $50 \mathrm{UI} / \mathrm{mL}$; estreptomicina $50 \mu \mathrm{g} / \mathrm{mL}$; FSH $0,5 \mu \mathrm{g} / \mathrm{mL}$; LH 5,0 $\mu \mathrm{g} / \mathrm{mL}$; piruvato de sódio 0,2 mM). A esse meio foi adicionado o CHIR99021 (Axon Medchem 1386, dissolvido em DMSO 99,7\%, segundo recomendações do fabricante - concentração estoque de $0,3 \mathrm{mM}$ ) em diferentes concentrações $(0,1,5 ; 3,0$ e $6,0 \mu \mathrm{M})$. As concentrações utilizadas foram baseadas no trabalho de Aparicio et al. (2010). A MIV foi realizada em incubadora, com atmosfera umidificada a 5\% de $\mathrm{CO}_{2}$, a $38,5^{\circ} \mathrm{C}$. Os oócitos foram mantidos nesta condição por $22 \mathrm{~h}$.

\section{Avaliação da expansão das células do cumulus}

Após a MIV, os CCOs foram classificados visualmente pelo mesmo observador, em cinco níveis de expansão das células do cumulus, sob estereomicroscópio, com aumento de 40x, usando como referência o grupo controle. $O$ menor grau de expansão foi classificado como um; a expansão das camadas externas foi classificada como grau dois; a expansão de todas as camadas, exceto a corona radiata foi classificada como grau três; e por fim, todas as camadas incluindo a corona, foi classificado como grau quatro (Tao et al., 2004).

\section{Avaliação da viabilidade celular}

Para avaliar a viabilidade celular, após o período de maturação, as células do cumulus dos CCOs foram removidas mecanicamente e os oócitos incubados em solução de calceína AM 1\% (Fluka) por 15 min. Em seguida, foram incubados em solução de iodeto de propídio 2\% por 10 min. Todas as marcações fluorescentes foram realizadas ao abrigo da luz. Foram considerados viáveis, os oócitos que emitiram fluorescência verde, pela calceína AM. Oócitos que não apresentaram fluorescência e células marcadas em vermelho pelo iodeto de propídio foram consideras inviáveis.

\section{Avaliação da formação da placa metafásica}

As células do cumulus dos CCOs foram removidas mecanicamentee os oócitos fixados em etanol/ácido acético (3:1). Após 48 h foram corados com orceína acética 2\% (Fluka) e observados em microscópio óptico para determinação da formação da placa metafásica. Foram considerados maturados os oócitos que apresentaram placa metafásica e/ou presença do corpúsculo polar.

\section{Avaliação da distribuição dos grânulos corticais}

Após $22 \mathrm{~h}$ de MIV, as células do cumulus dos CCOs foram removidas mecanicamente e a zona pelúcida removida pela incubação dos oócitos em solução de pronase E $0,5 \%$. Os oócitos foram então fixados em paraformaldeído $3 \%$, à temperatura ambiente, por $30 \mathrm{~min}$. Em seguida, foram permeabilizados em solução de Triton X100 0,1\%, por 5 min. Posteriormente, foram incubados com lectina Lens culinaris-FITC 2,5\% (Vector), a $37{ }^{\circ} \mathrm{C}$, ao abrigo da luz, por $30 \mathrm{~min}$. As amostras foram analisadas em microscópio de fluorescência, e a distribuição periférica dos grânulos corticais foi considerada como um indicativo de maturação citoplasmática.

\section{Fertilização in vitro (FIV) e cultivo in vitro (CIV)}

Espermatozoides viáveis foram selecionados pelo gradiente descontínuo de Percoll 90/45\%, e co-incubados com os CCOs $(20 \mathrm{CCOs} /$ gota) maturados in vitro, em gotas de $50 \mu \mathrm{L}$ de meio Talp-fert (BSA livre de ácidos graxos $0,006 \mathrm{~g} / \mathrm{mL}$, piruvato de sódio 0,2 mM, $\mathrm{NaCl}$ 0,9\%, heparina $20 \mathrm{mg} / \mathrm{mL}$, penicilamina $1 \mathrm{mM}$, hipotaurina $2 \mathrm{mM}$, epinefrina $250 \mathrm{mM}$, gentamicina $0,2 \mathrm{mM}$ ). Foi utilizada a concentração espermática de $2 \times 10^{6} \mathrm{~mL}^{-1}$. A FIV foi realizada em incubadora de $\mathrm{CO}_{2}$, com atmosfera umidificada a $5 \%$ de $\mathrm{CO}_{2}$, a $38,5{ }^{\circ} \mathrm{C}$, durante $18 \mathrm{~h}$. Os supostos zigotos $(20 /$ gota de $100 \mu \mathrm{L})$ foram 
Barroso et al. Maturação in vitro de oócitos bovinos é negativamente afetada por CHIR99021, inibidor específico de GSK3

cultivados em meio SOF (BSA livre de ácidos graxos $0,004 \mathrm{~g} / \mathrm{mL}$, piruvato de sódio $0,4 \mathrm{mM}$, glutamina $100 \mathrm{mM}$, BME $100 \mu \mathrm{L} / \mathrm{mL}$, MEM $50 \mu \mathrm{L} / \mathrm{mL}$, soro fetal bovino 2,5\%, penicilina $50 \mathrm{UI} / \mathrm{mL}$ ) e mantidos por sete dias em incubadora, nas mesmas condições da FIV. No quarto dia foi feita a troca de $50 \%$ do meio de cultivo e realizada a avaliação da taxa de clivagem. No sétimo dia foi determinada a porcentagem de blastocistos.

\section{Análise estatística}

Os experimentos foram conduzidos em delineamento inteiramente casualizado e os resultados obtidos de quatro réplicas independentes foram submetidos ao teste de normalidade Shapiro-Wilk, seguido de ANOVA a $1 \%$ de significância $(\mathrm{p} \leq 0,01)$. A comparação entre os tratamentos foi determinada por regressão linear por equação de $1^{\circ}$ grau, a $1 \%$ de significância $(p \leq 0,01)$. O programa utilizado foi o GraphPrism versão 5.0 e os dados apresentados como média \pm desvio padrão.

\section{Resultados}

\section{Efeito do CHIR99021 no grau de expansão das células do cumulus}

O grau de expansão das células do cumulus não diferiu entre o grupo controle e o grupo em que foi utilizada a menor concentração de CHIR99021 $(1,5 \mu \mathrm{M})$. Porém, foi observado que as células do cumulus se desprenderam com maior facilidade, se comparado ao controle, durante as manipulações para desnudamento do oócito. Em ambos os grupos, a expansão das células do cumulus foi avaliada como grau 4. A expansão das células do cumulus dos CCOs tratados com 3,0 e 6,0 $\mu \mathrm{M}$ do inibidor foi menor, grau 2 e 1 respectivamente, apresentando elevada sensibilidade ao desnudamento mecânico (Fig. 1).

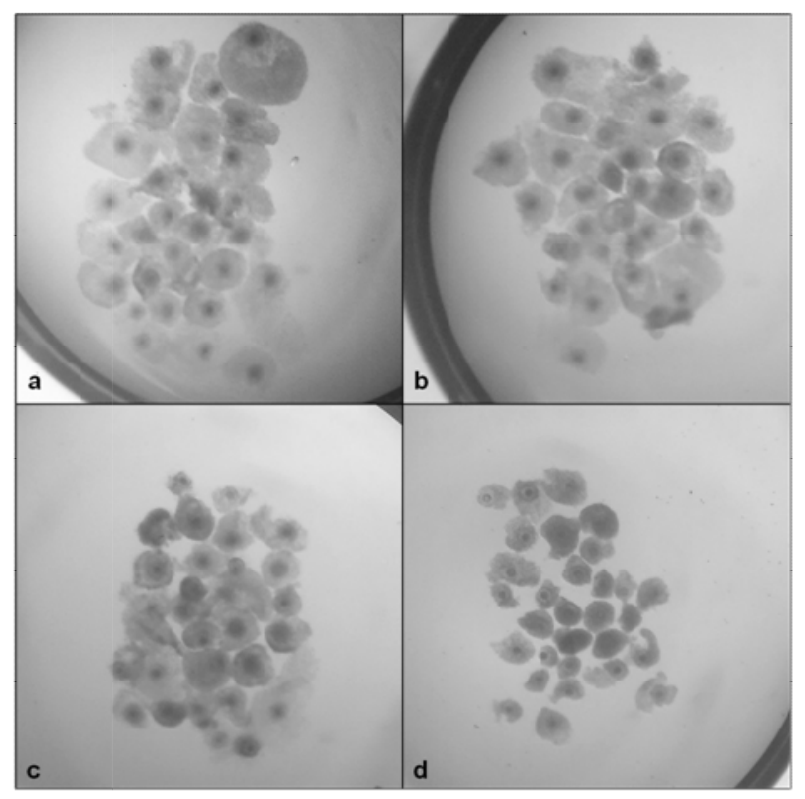

Figura 1. Imagem representativa do grau de expansão das células do cumulus nos CCOs controle (a), e tratados com 1,5 (b), 3,0 (c) e 6,0 $\mu \mathrm{M}$ (d) de CHIR99021, após 22 h de MIV ( $\mathrm{n}=$ média de 30 oócitos por tratamento). Aumento de 40x.

\section{Avaliação da viabilidade dos oócitos maturados}

A marcação fluorescente com calceína AM e iodeto de propídio revelou um efeito dosedependente do CHIR99021 sobre a viabilidade dos oócitos maturados. Oócitos do grupo controle apresentaram maiores taxas de viabilidade se comparado aos oócitos dos demais grupos. A maior concentração de CHIR99021 $(6,0 \mu \mathrm{M})$ utilizada reduziu em 42,7\% o número de oócitos viáveis em relação ao controle (Fig. 2). 
Barroso et al. Maturação in vitro de oócitos bovinos é negativamente afetada por CHIR99021, inibidor específico de GSK3

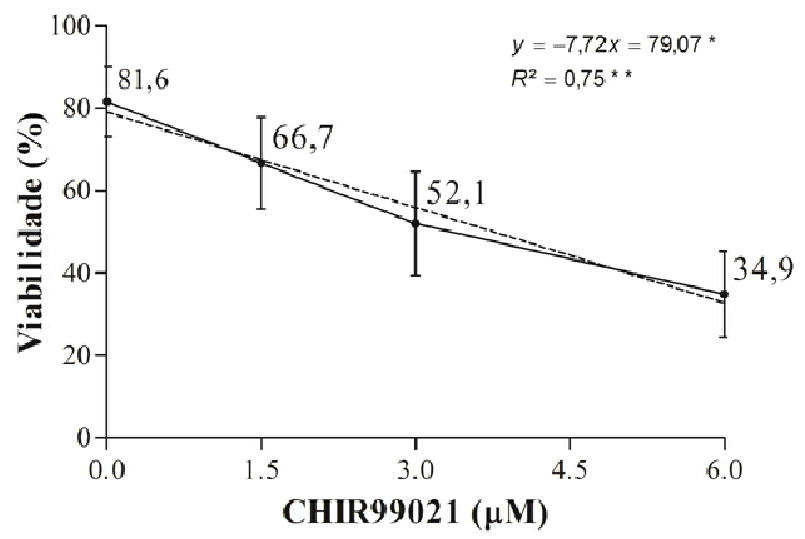

Figura 2. Efeito das concentrações crescentes de CHIR99021 na viabilidade de oócitos bovinos, após $22 \mathrm{~h}$ ( $\mathrm{n}=278$, média de 70 oócitos por tratamento). (*) Efeito significativo $(\mathrm{p} \leq 0,01)$ para a contribuição dos termos de $\mathrm{B}_{0}$ e $\mathrm{B}_{1}$ ao modelo de regressão, segundo o Teste $\mathrm{t} ;(* *)$ e para o coeficiente de regressão $\left(\mathrm{R}^{2}\right)$, segundo o Teste F. A linha contínua refere-se à média de cada tratamento e a linha pontilhada refere-se à equação da reta.

\section{Avaliação da progressão da meiose e da redistribuição dos grânulos corticais após a MIV}

Os tratamentos dos CCOs com 1,5 e 3,0 $\mu \mathrm{M}$ de CHIR99021 durante a MIV reduziram significativamente o percentual de oócitos que progrediram até a metáfase II quando comparado ao grupo controle. Esta redução foi ainda mais pronunciada quando a maior concentração do inibidor $(6,0 \mu \mathrm{M})$ foi utilizada, diferindo significativamente, tanto do grupo controle, como das demais concentrações do inibidor (Fig. 3a). A migração dos grânulos corticais não foi afetada pelo tratamento dos CCOs com 1,5 $\mu \mathrm{M}$ do inibidor. Por outro lado, os grupos tratados com 3,0 e 6,0 $\mu \mathrm{M}$ apresentaram redução do percentual de oócitos que apresentaram distribuição periférica dos grânulos corticais após a MIV (Fig. 3b).

a

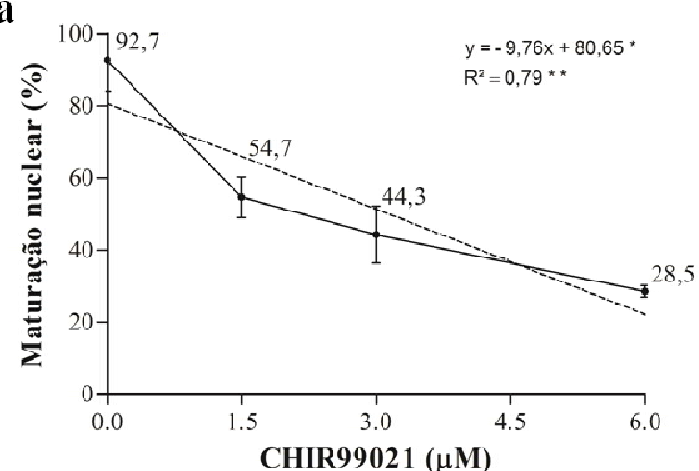

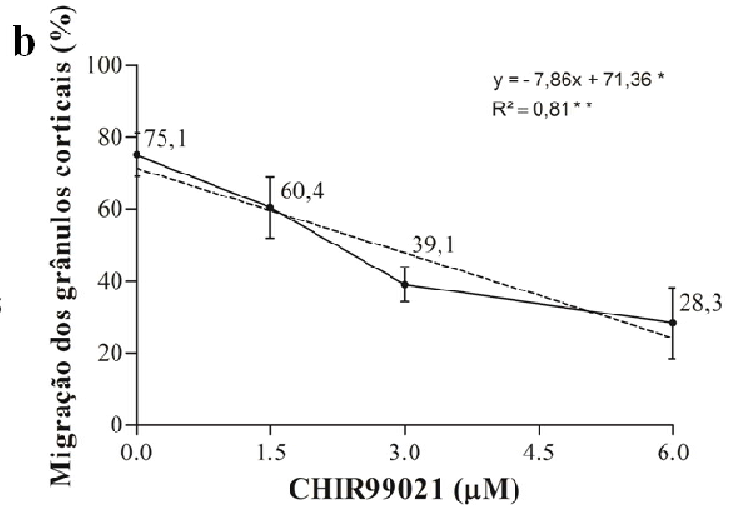

Figura 3. Efeito das concentrações crescentes de CHIR99021 na progressão da meiose ( $\mathrm{n}=168$, média de 40 oócitos por tratamento) (a) e migração de grânulos corticais $(n=203$, média de 50 oócitos por tratamento) (b) de oócitos bovinos, após 22 h de MIV.(*) Efeito significativo $(\mathrm{p} \leq 0,01)$ para a contribuição dos termos de $\mathrm{B}_{0}$ e $\mathrm{B}_{1}$ ao modelo de regressão, segundo o Teste $\mathrm{t}$; $\left({ }^{*}\right)$ e para o coeficiente de regressão $\left(\mathrm{R}^{2}\right)$, segundo o Teste $\mathrm{F}$. A linha contínua refere-se à média de cada tratamento e a linha pontilhada refere-se à equação da reta.

\section{Efeito do CHIR99021 na PIV}

Oócitos do grupo controle e tratados com 1,5 $\mu \mathrm{M}$ de CHIR99021 durante a MIV não diferiram significativamente em relação à taxa de clivagem e produção de blastocisto (Fig. 4a). Porém, aqueles 
Barroso et al. Maturação in vitro de oócitos bovinos é negativamente afetada por CHIR99021, inibidor específico de GSK3

tratados com 3,0 e 6,0 $\mu \mathrm{M}$ apresentaram redução no percentual de clivagem e na taxa de blastocistos (Fig. $4 b)$.
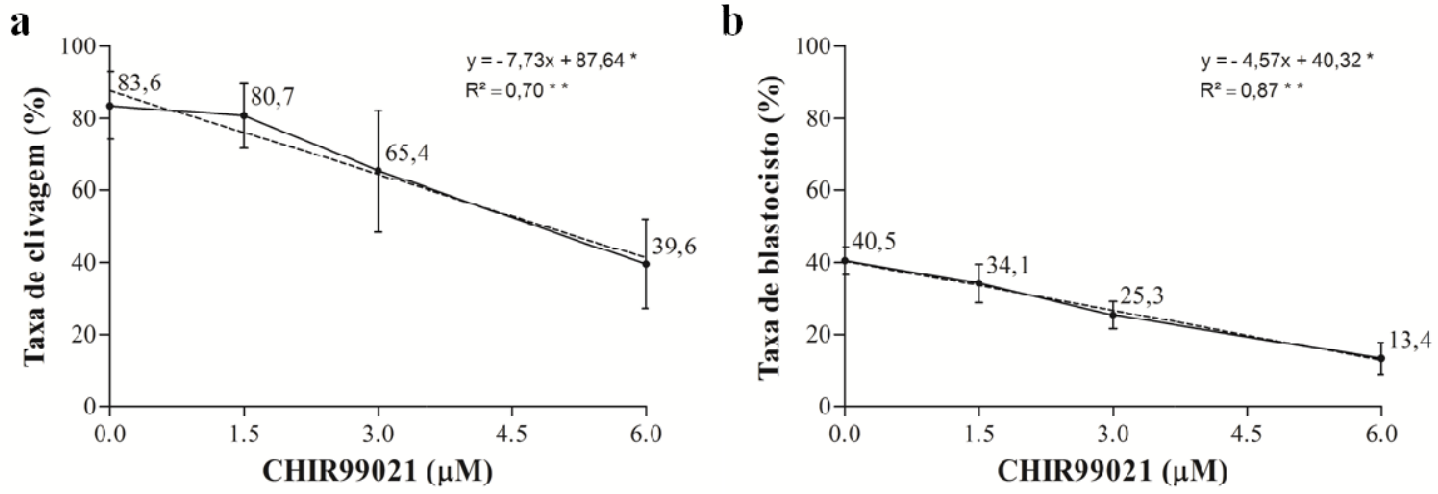

Figura 4. Taxas de clivagem (a) e de blastocistos ( $n=330$, média de 80 oócitos por tratamento) (b) produzidos a partir de oócitos bovinos maturados in vitro com diferentes concentrações de CHIR99021.(*) Efeito significativo $(\mathrm{p} \leq 0,01)$ para a contribuição dos termos de $\mathrm{B}_{0}$ e $\mathrm{B}_{1}$ ao modelo de regressão, segundo o Teste t; (**) e para o coeficiente de regressão $\left(\mathrm{R}^{2}\right)$, segundo o Teste $\mathrm{F}$. A linha contínua refere-se à média de cada tratamento e a linha pontilhada refere-se à equação da reta.

\section{Discussão}

Neste trabalho foi avaliado o efeito do CHIR99021, um inibidor específico da atividade da GSK3, sob a expansão das células do cumulus, a viabilidade oocitária, a maturação nuclear, a migração de grânulos corticais e a PIV de embriões, na tentativa de aumentar o conhecimento da participação desta enzima durante a MIV de oócitos bovinos e o seu efeito no desenvolvimento embrionário inicial.

O CCO é formado por dois tipos celulares com necessidades metabólicas diferentes: i) as células do cumulus têm elevada demanda por glicose, enquanto ii) os oócitos requerem metabólitos provenientes do metabolismo oxidativo. Apesar disso, ambos os compartimentos atuam em cooperação para que o oócito esteja apto para suportar o desenvolvimento embrionário (Gilchrist e Thompson, 2007). Durante a MIV, as células do cumulus sofrem importantes modificações, em que a mais aparente delas é a expansão que ocorre devido à síntese de ácido hialurônico e representa o fim da cooperação entre as células do cumulus e o oócito (Collado-Fernandez et al., 2013).

Quando as concentrações de 3,0 e 6,0 $\mu \mathrm{M}$ de CHIR99021 foram adicionadas ao meio de MIV houve uma redução do grau de expansão das células do cumulus e uma redução dose dependente da viabilidade oocitária. Fisiologicamente, quando fatores de crescimento como epidermel growth fator (EGF) ou a insulina ativam a via PI3K/AKT, a GSK3 é fosforilada, inibida e deixa de fosforilar a glicogênio sintase, que está livre para desempenhar sua função: a produção de glicogênio (Beurel et al., 2015). No presente estudo, os CCOs foram mantidos na presença do inibidor desde o início do processo de maturação, e possivelmente as fontes energéticas suplementadas no meio de cultivo, através do soro fetal bovino e do piruvato, foram utilizadas para formar glicogênio, forma esta, que não está prontamente disponível para uso nas células. Desta forma, sugere-se que o uso do CHIR99021 pode ter ocasionado privação energética nas células do cumulus justificando a falha na expansão, e consequentemente redução na oferta de metabólitos importantes para a maturação, como aminoácidos e intermediários do ciclo do ácido tricarboxílico (TCA), que por sua vez comprometeu a viabilidade ovocitária (Gutniskyet al., 2007; Sutton-McDowall et al., 2010). Em células tronco de camundongos, na presença de CHIR99021, a viabilidade de células ES-D3 foi reduzida a 24,7\% com $2,5 \mu \mathrm{M}, 56,3 \% \operatorname{com} 5 \mu \mathrm{M}, 61,9 \%$ com $7,5 \mu \mathrm{M}$ e $69,2 \%$ com $10 \mu \mathrm{M}$ (Naujok et al., 2014).

Uzbekova et al. (2009) também reportaram uma redução da expansão das células do cumulus após a MIV de CCOs bovinos na presença de $\mathrm{LiCl}_{2}$ e $\mathrm{BIO}$, inibidores da GSK3. Segundo estes autores, há uma relação ainda não totalmente elucidada entre a GSK3 $\beta$ e a proteína quinase ativada por mitógeno14 (MAPK14) na expansão dessas células e a transição MI-MII durante a MIV. Neste tipo celular, a MAPK14 torna-se progressivamente fosforilada até 6-10 h de MIV (transição VGBD-MI). Após esse 
período a fosforilação reduz drasticamente, correspondendo ao fechamento das junções do tipo gap e expansão das células do cumulus. $\mathrm{O}$ uso do $\mathrm{LiCl}_{2}$ e $6 \mathrm{BIO}$, aumentou significativamente a fosforilação de MAPK14 inibindo a expansão das células do cumulus. Além disso, esses autores detectaram que na presença de lítio, a secreção de progesterona pelo $\mathrm{CCO}$ foi reduzida, afetando a proliferação celular.

O tratamento dos CCOs com CHIR99021 também promoveu uma redução dose-dependente da maturação nuclear. A retomada da meiose e progressão ao estádio de metáfase II envolve complexos eventos de fosforilação e desfosforilação de quinases que controlam o fuso meiótico para que ocorra a segregação adequada dos cromossomos e preparação do oócito para a fertilização (Kinsey, 2014). Em oócitos competentes de camundongos GSK3 foi identificada na região de peri-oolema e sua inibição pelo $\mathrm{LiCl}_{2}$ levou a formação anormal do fuso e aumentou significativamente a incidência de segregação anormal dos cromossomos homólogos durante a primeira divisão meiótica (Wang et al., 2003). Zhang et al. (2017) também demonstraram que a inibição da GSK3 reduziu a progressão da meiose e a porcentagem de extrusão do primeiro corpúsculo polar em oócitos murinos. Em bovinos, GSK3 $\beta$ foi identificada próxima à região do corpúsculo polar em oócitos maturados, e sua inibição com $\mathrm{LiCl}_{2}$ apresentou somente $14 \%$ de maturação comparado com o controle. Entretanto, quando o inibidor específico BIO foi utilizado, a redução da maturação foi dose-dependente (Uzbekovaet al., 2009), conforme observado em nosso estudo. Segundo Baluch e Capco (2008), GSK3 $\alpha$ também está envolvida na estabilização de microtúbulos no estádio de metáfase II, por meio da participação da proteína quinase C (p-PKC ). Quando a GSK3 $\alpha$ está desfosforilada o fuso é desestabilizado, por outro lado, quando está fosforilada ocorre a estabilização do fuso e manutenção da placa metafásica. Desta forma, o uso do CHIR99021 pode ter afetado a dinâmica de estabilização/desestabilização de microtúbulos, devido à participação dessa enzima na fosforilação de outras enzimas do tipo quinase, promovendo uma redução significativa dos oócitos que atingiram o estádio de metáfase II, conforme demonstram outros estudos utilizando inibidores de GSK3.

Além da redução da maturação nuclear, o uso do inibidor nas concentrações de 3,0 e 6,0 $\mu \mathrm{M}$ comprometeu significativamente a redistribuição dos grânulos corticais. Tem sido demostrado, que cerca de $80 \%$ dos oócitos maturados in vitro atingem a maturação nuclear, porém apenas cerca de $60 \%$ destes alcançam a maturação citoplasmática. Em oócitos não maturados, os grânulos corticais apresentam-se distribuídos em clusters pelo citoplasma, mas ao atingir o estádio de MII, ficam distribuídos ao longo da membrana plasmática afim de desempenhar sua função de bloqueio à poliespermia (Sun et al. 2002). Tais organelas são transportadas por meio da polimerização e despolimerização dos microfilamentos de actina e a correta distribuição destes é considerada como um importante marcador de maturação citoplasmática (Liu, 2011). Tatebayashi et al. (2004) relataram que a inibição de GSK3 alterou o transporte de mitocôndrias pelo citoplasma em células PC12. De acordo com o nosso conhecimento este é o primeiro trabalho que demonstra oenvolvimento da GSK3 na migração dos grânulos corticais, porém mais estudos são necessários para entender se tal efeito é devido à participação dessa enzima na dinâmica dos microfilamentos. O entendimento de como GSK3 atua na reestruturação do citosol pode contribuir para melhorar as condições de PIV, e consequentemente a obtenção de embriões de melhor qualidade.

Quando CCOs tratados com 3,0 e 6,0 $\mu \mathrm{M}$ do CHIR99021 durante a MIV foram utilizados para a PIV de embriões houve uma redução significativa nas taxas de clivagem e de blastocistos no quarto e sétimo dia do desenvolvimento, respectivamente. Tais resultados podem ser atribuídos às alterações enzimáticas que comprometeram a viabilidade, a maturação nuclear e citoplasmática. O efeito inibitório provocado pelo CHIR99021 na GSK3 também pode ter afetado a regulação de fatores de transcrição associados a essa enzima, tais como ciclina D1, c-Jun, Mlc-1, HSF-1 e c-Myc. Tais proteínas participam da diferenciação e proliferação celular, regulando a expresão de genes importantes para o desenvolvimento embrionário, como SOX2, NANOG e OCT4 (Sutherland, 2011; Verma et al., 2013). In vivo, o aumento da inibição da GSK3 após a quebra da vesícula verminativa, através da cascata de fosforilação enzimática, faz com que a $\beta$-catenina estimule a transcrição dos genes Wnts (Tribulo et al., 2017a, 2017b). Estes genes participam dos processos de diferenciação, proliferação celular e apoptose, durante o desenvolvimento embrionário. Em celulas embrionárias, a inibição de GSK3 com $5 \mu \mathrm{M}$ de CHIR99021 resultou na ativação da via WNT/ $\beta$-catenina e expressão aumentada dos genes $T, N A N O G$ e POU5F1 relacionados a essa via (Naujok et al., 2014). Assim, sugere-se que a utilização do inibidor de GSK3 desde o início da maturação pode promover a transcrição inadequada desses genes, afetando toda a PIV. Apesar disso, ressalta-se que diferentes vias de sinalização estão envolvidas no controle da maturação de oócitos e a fosforilação reversivel de enzimas do tipo quinases, através da modulação de sua atividade, pode ser uma importante ferramenta para aumentar a eficácia e a qualidade da PIV. 
Barroso et al. Maturação in vitro de oócitos bovinos é negativamente afetada por CHIR99021, inibidor específico de GSK3

\section{Conclusões}

Conclui-se que o CHIR99021 interfere negativamente, de forma dose-dependente na MIV de oócitos bovinos, sugerindo a importância da GSK3 na maturação nuclear e citoplasmática, com consequente impacto para a PIV de embriões bovinos.

\section{Agradecimentos}

Este estudo foi financiado em pelo Conselho Nacional de Desenvolvimento Científico e Tecnológico $(\mathrm{CNPq})$ e Fundação de Amparo à Pesquisa do Estado do Rio de Janeiro (FAPERJ - E26/102.943/2012).

\section{Referências}

Acevedo N, Wang X, Dunn RL, Smith GD. Glycogen synthase kinase-3 regulation of chromatin segregation and cytokinesis in mouse pre implantation embryos. Mol Reprod Dev: Incorporating Gamete Research, v.74, n.2, p.178-188, 2007.

Aparicio IM, Garcia-Herreros M, Fair T, Lonergan P. Identification and regulation of glycogen synthase kinase-3 during bovine embryo development. Reproduction, v.140, n.1, p.83-92, 2010.

Bain J, Plater L, Elliot M, Shpiro N, Hastie CJ, Mclauchlan H, Klevernic I, Arthur SC, Alessi DR, Cohen P. The selectivity of protein kinase inhibitors: a further update. Biochem J, v.408, n.3, p.297-315, 2007.

Baluch DP, Capco DG. GSK3 $\beta$ mediates a centromeric spindle stabilization by activated PKC $\zeta$. Dev Biol, v.317, n.1, p.46-58, 2008.

Beurel E, Grieco SF, Jope RS. Glycogen synthase kinase-3 (GSK3): Regulation, actions, and diseases. Pharmacol Ther, v.148, p.114-131,2015.

Cohen P, Frame S. The renaissance of GSK3. Nat Rev Mol Cell Biol., v.2, n.10, p.769-776, 2001.

Collado-Fernandez E, Picton HM, Dumollard R. Metabolism through out follicle and oocyte development in mammals. Int J Dev Biol, v.56, n.10-11-12, p.799-808, 2013.

Cormier KW, Woodgett JR. Recent advances in understanding the cellular roles of GSK-3. F1000research, v.6, p.167-173, 2017.

Embi N, Rylatt DB, Cohen P. Glycogen synthase kinase-3 from rabbit skeletal muscle. Euro J Biochem, v.107, n.2, p.519-527, 1980

Forde JE, Dale TC. Glycogen synthase kinase 3: A key regulator of cellular fate. Cell Mol Life Sci, v. 64, n.15, p.1930-1944, 2007.

Gilchrist RB, Thompson JG. Oocyte maturation: Emerging concepts and technologies to improve developmental potential in vitro. Theriogenology, v.67, n.1, p.6-15, 2007.

Gutnisky C, Dalvit GC, Pintos LN, Thompson JG, Beconi MT, Cetica PD. Influence of hyaluronic acid synthesis and cumulus mucification on bovine oocyte in vitro maturation, fertilisation and embryo development. Reprod Fertil Dev, v.19, n.3, p.488-497, 2007.

Jope RS. Lithium and GSK-3: one inhibitor, two inhibitory actions, multiple outcomes. Trends Pharmacol Sci, v.24, n.9, p.441-443, 2003.

Kinsey WH. Src-Family tyrosine kinases in oogenesis, oocyte maturation and fertilization: $\mathrm{Na}$ evolutionary perspective. Adv Exp Med Biol, p.33-56, 2014.

Liu M. The biology and dynamics of mammalian cortical granules. Reprod Biol Endocrinol, v.9, n.1, p. 149-166, 2011.

Naujok O, Lentes J, Diekmann U, Davenport C, Lenzen S. Cytotoxicity and activation of the Wnt/beta-catenin pathway in mouse embryonic stem cells treated with four GSK3 inhibitors. Bmc Res Notes, v.7, n.1, p.273-280, 2014.

Pelech S, Jelinkova L, Susor A, Zhang H, Shi X, Pavlok A, Kubelka M, Kovarova H. Antibody microarray analyses of signal transduction protein expression. And phosphorylation during porcine oocyte maturation. J Proteome Res, v.7, n.7, p.2860-2871, 2008.

Ring DB, Johnson KW, Henriksen EJ, Nuss JM, Goff D, Kinnick TR, Ma ST, Reeder JW, Samuels I, Slabiak T, Wagman AS, Hammond ME, Harrison SD. Selective glycogen synthase kinase-3 inhibitors potentiate insulin activation of glucose transport and utilization in vitro and in vivo. Diabetes, v.52, n.3, p.588-595, 2003. 
Barroso et al. Maturação in vitro de oócitos bovinos é negativamente afetada por CHIR99021, inibidor específico de GSK3

Sarkissian M, Mendez R, Richter JD. Progesterone and insulin stimulation of CPEB-dependent polyadenylation is regulated by Aurora A and glycogen synthase kinase-3. Genes Dev, v.18, n.1, p.48-61, 2004.

Sklirou AD, Gaboriaud-Kolar N, Papassideri I, Skaltsounis AL, Trougakos IP. 6-bromo-indirubin3 '-oxime (6BIO), a glycogen synthase kinase-3 $\beta$ inhibitor, activates cytoprotective cellular modules and suppresses cellular senescence-mediated biomolecular damage in human fibroblasts. Sci Rep, v.7, n.1, p.11713-11726, 2017.

Sun QY, Wu GM, Lai L, Bonk A, Cabot R, Park KW, Day BN, Prather RS, Schatten H. Regulation of mitogen activated protein kinase phosphorylation, microtubule organization, chromatin behavior, and cell cycle progression by protein phosphatases during pig oocyte maturation and fertilization in vitro. Biol Reprod, v.66, n.3, p.580-588, 2002.

Sutherland C. What are the bona fide GSK3 substrates? Int J Alzheimer's Dis, v.2011, p.1-23, 2011.

Sutton-McDowall ML, Gilchrist RB, Thompson JG. The pivotal role of glucose metabolism in determinin go ocyte developmental competence. Reproduction, v.139, n.4, p.685, 2010.

Tatebayashi Y, Haque N, Tung YC, Iqbal K, Grundke-Iqbal I. Role of tau phosphorylation by glycogen synthase kinase-3 $\beta$ in the regulation of organelle transport. J Cell Sci, v.117, n.9, p.1653-1663, 2004.

Tao Y, Xia G, Bo S, Zhou B, Zhang M, Wang F. Nitric oxide exerts different functions on porcine oocytes cultured in different models, which is affected by beta-mercaptoethanol. Asian-australasian $\mathrm{J}$ Anim Sci, v.17, n.3, p.317-324, 2004.

Tomek W, Smiljakovic T. Activation of Akt (protein kinase B) stimulates metaphase I to metaphase II transition in bovine oocytes. Reproduction, v.130, n.4, p.423-430, 2005.

Tribulo P, Leão BCDS, Lehloenya KC, Mingoti GZ, Hansen PJ. Consequences of endogenous and exogenous WNT signaling for development of the preimplantation bovine embryo $†$.Biol Reprod, v. 96, n.6, p.1129-1141, 2017a.

Tribulo P, Moss JI, Ozawa M, Jiang Z, Tian XC, Hansen PJ. WNT regulation of embryonic development likely involves pathways independente of nuclear CTNNB1. Reproduction, v.153, n.4, p.405-419, 2017b.

Uzbekova S, Salhab M, Perreau C, Mermillod P, Dupont J. Glycogen synthase kinase 3B in bovine oocytes and granulosa cells: possible involvement in meiosis during in vitro maturation. Reproduction, v.138, n.2, p.235-246, 2009.

Verma V, Huang B, Kallingappa PK, Oback B. Dual kinase inhibition promotes pluripotency in finite bovine embryonic cell lines. Stem Cells Dev, v.22, n.11, p.1728-1742, 2013.

Wang X, Liu XT, Dunn R, Ohl DA, Smith GD. Glycogen synthase kinase-3 regulates mouse oocyte homologue segregation. Mol Reprod Dev, v.64, n.1, p.96-105, 2003.

Woodgett JR. Molecular cloning and expression of glycogen synthase kinase-3/factor A. Embo J, v.8, n.9, p.2431-2438, 1990.

Zhang XL, Liu P, Yang ZX, Zhao JJ, Gao LL, Yuan B, Shi LY, Zhou CX, Qiao HF, Liu YH, Ying XY, Zhang JQ, Ling XF, Zhang D. Pnma5 is essential to the progression of meiosis in mouse oocytes through a chain of phosphorylation. Oncotarget, v.8, n.57, p.96809-96825, 2017. 